\title{
Trends in Piezoelectric Devices for Biomedical Applications
}

\author{
Kenji Uchino* \\ Professor, Electrical Engineering, USA
}

Submission: July 05, 2017; Published: July 20, 2017

*Corresponding author: Kenji Uchino, Professor, Electrical Engineering, Director, International Center for Actuators and Transducers, The Pennsylvania State University, University Park, PA 16802, USA, Email: kenjiuchino@psu.edu

\section{Opinion}

It is my pleasure to write my opinion on the trends in piezoelectric devices for biomedical applications. For this issue, I would like to point out five key words for providing the future perspectives of research trends in order for materials scientists to understand the development direction; "Performance to Reliability", "Hard to Soft", "Macro to Nano", "Homo to Hetero" and "Single to Multi-functional", which have been extracted in particular from my expert area, piezoelectric materials. This is just a summary article because the details have already been published in several papers, some of which are listed in the last references.

\section{Performance to Reliability}

What will you react if your mainstream material would be restricted to use tomorrow? In 2006, European Community started RoHS (Restrictions on the use of certain Hazardous Substances), which restrictsalso the usage of lead $(\mathrm{Pb})$ in electronic equipment, including our major lead zirconatetitanate $\left(\mathrm{Pb}(\mathrm{Zr}, \mathrm{Ti}) \mathrm{O}_{3}, \mathrm{PZT}\right)$ in the near future. This target is focused particularly in the medical applications, which may be embedded in human body. Pb-free piezoceramics have started to be developed after 1999, which are classified basically into three groups; $(\mathrm{Bi}, \mathrm{Na}) \mathrm{TiO}_{3}(\mathrm{BNT}),(\mathrm{Na}, \mathrm{K}) \mathrm{NbO}_{3}(\mathrm{NKN})$ and tungsten bronze (TB), most of which are revival materials after the 1970s.Though none of $\mathrm{Pb}$-free piezoelectrics exceeds the PZT performances at present, $(\mathrm{Na}, \mathrm{K}) \mathrm{NbO}_{3}$ systems exhibit the highest propertyamong the present $\mathrm{Pb}$-free materials, because of the morphotropic phase boundary usage. Tungsten-bronze types are another alternative choice for resonance applications, since a sophisticated preparation technology for oriented ceramics with a multilayer configuration has been developed: that is, preparation under strong magnetic field. By extending the non-toxic idea, bio-degradable piezo-materials are in the focus, among which L-type poly-lactic acid (PLLA) is made of vegetable corn based composition. High power piezoelectrics with low loss have also become a central research topic from the energy-efficiency improvement viewpoint; that is to say, the target is gradually shifting from "real (strain magnitude) to imaginary performance (heat generation reduction)". Reducing hysteresis and increasing the mechanical quality factor to amplify the resonance displacement is our primary target from the transducer application viewpoint.

\section{Hard to Soft}

We are facing the revival polymer era after the 1980s because of their elastically soft superiority. Larger, thinner, lighter and mechanically flexible human interfaces are the current necessity in portable electronic devices, leading to the development in elastically soft displays, electronic circuits, speakers/microphones, and tactic/haptic functions. This is a general direction of piezoelectric devices as human interface transducers. Dielectric elastomer actuators (non-piezoelectric, non-ferroelectric) are based on the deformation of a soft polymer which acts as a dielectric between highly compliant electrodes. In-plane strains of more than 100\% (doubled stretch!) are observed in silicone elastomers. Polyvinylidene difluoride-trifluoroethylene (PVDF-TrFE) copolymer is a wellknown piezoelectric, which has been popularly used in sensor applications such as keyboards. New bendable and foldable speakers with using a 0:3 composite (i.e., PZT fine powder mixed in a polymer film) provide superior acoustic performance, very promising for flat-speaker applications.Relaxor-PbTiO3 single crystals, includingPb(Zn1/3Nb2/3)03-PbTiO3 (PZNPT) became popular due to the rubber-like-soft piezo-ceramic strain after 25 years of our discovery. We firstly reported in 1981 an enormously large electromechanical coupling factor $\mathrm{k} 33=92 \sim 95 \%$ and piezoelectric constant $\mathrm{d} 33=1500 \mathrm{pC} / \mathrm{N}$ in these solid solution crystals. The strains as large as $1.7 \%$ can be induced practically in the PZN-PT crystals.

\section{Macro to Nano}

In the Micro (Nano) Electro-Mechanical System (MEMS/ NEMS) area, the piezoelectric-film deposited silicon device is one of the miniaturization targets for integrating the piezo-actuators 
in a micro-scale chip, aiming at bio/medical applications in particular. After our proto-type micro-pumps for blood test with PZT sputtered films in the early 1990s, you can now find many papers on piezoelectric-MEMS/NEMS published in various journals, including this "Nanotechnology and Material Science". The essential development issues include [1] how to increase the film thickness (i.e., PZT volume) to increase the handling energy level for actuator applications. Though the nano-meter thin piezo films can be used as sensors, the actuator application requires $1 \mathrm{~mW}$ level energy from a practical usage viewpoint, leading $0.1 \mathrm{~mm} 3$ volume of PZT minimum [2]. How to connect thousands of micro devices in parallel or series synchronously of each with only nano to micro watt energy level.

\section{Homo to Hetero}

A recent research trend can also be found in "Homo to hetero" structure change: Stress-gradient in terms of space in a dielectric material can exhibit piezoelectric-equivalent sensing capability (called "flexoelectricity"); while electric-field gradient in terms of space in a semiconductive piezoelectric exhibits bimorphequivalent flextensional deformation (i.e., "monomorph"). Such a monomorph device can be produced from just a single ceramic plate without laborious lamination process. The operating principle is based on the combined action of a semiconductor contact phenomenon (Schottky barrier) and the piezoelectric effect.

\section{Single to Multi-Functional}

Some new functions can be realized by coupling two effects. Our Penn State group developed magnetoelectric devices (i.e., voltage is generated by applying magnetic field) by laminating magnetostrictive Terfenol-D and piezoelectric PZT materials, and demonstrated photostriction by coupling photovoltaic and piezoelectric effects in PLZT (La-doped PZT). Magnetic field may increase the cancer incidence rate, though the evidences are not definite. Similar to nuclear radiation, magnetic irradiation cannot be felt by human. We cannot even purchase a magnetic field detector for a low frequency (50 or $60 \mathrm{~Hz}$ ). We developed a simple and handy magnetic noise sensor for these environmental monitoring purpose, e.g., below a highvoltage power transmission line. A PZT disk is sandwiched by two Terfenol-D (magnetostrictor) disks. When a magnetic field is applied on this composite, Terfenol will expands, which is mechanically transferred to PZT, leading to an electric charge generation from the PZT. By monitoring the voltage generated in the PZT, we can detect the magnetic field. A photostrictive actuator is a fine example of an intelligent material, incorporating "illumination sensing" and self-production of "drive/control voltage" together with final "actuation". In certain ferroelectrics, a constant electromotive force is generated with exposure of light, and a photostrictive strain results from the coupling of this bulk photovoltaic effect with inverse piezoelectricity. Note that two effects are superposed in a uniform material in this case. A bimorph unit has been made from the PLZT ceramic. The remnant polarization of one PLZT layer is parallel to the plate and in the direction opposite to that of the other plate. When a violet light is irradiated to one side of the PLZT bimorph, a photovoltage of 1 $\mathrm{kV} / \mathrm{mm}$ is generated, causing a bending motion. A photo-driven micro walking device, designed to begin moving by alternate light illumination, has been developed. Photo-driven mechanical actuation may be integrated in medical endoscopes or catheters in the future. Our pioneering papers on both multi-functional materials and composites have been dramatically cited recently again 25 years after our invention/discovery.

It seems to be "Renaissance (revival)" of piezoelectric materials and composites in this new decade, a quarter century (i.e., one human generation) after the discovery.

\section{References}

1. Uchino K (2014) Piezoelectric Actuator Renaissance. J Energy Harvesting and Systems 1(1-2): 45-56.

2. Uchino K (2015) Piezoelectric Actuator Renaissance. Phase Transitions-A Multinational Journal 88(3): 1-10.

\section{Your next submission with Juniper Publishers} will reach you the below assets

- Quality Editorial service

- Swift Peer Review

- Reprints availability

- E-prints Service

- Manuscript Podcast for convenient understanding

- Global attainment for your research

- Manuscript accessibility in different formats

( Pdf, E-pub, Full Text, Audio)

- Unceasing customer service

Track the below URL for one-step submission https://juniperpublishers.com/online-submission.php 